\title{
Adoção de práticas de Green Supply Chain Management: mecanismos de indução e a importância das empresas focais
}

\author{
Ariana Fernandes Arantes ${ }^{\mathrm{a}}$, Ana Beatriz Lopes de Sousa Jabbour ${ }^{\mathrm{b}}$, \\ Charbel José Chiappetta Jabbour ${ }^{\mathrm{c} *}$ \\ aarikathebest@hotmail.com, UNESP, Brasil \\ bablsjabbour@gmail.com, UNESP, Brasil \\ c*prof.charbel@gmail.com, UNESP, Brasil
}

\section{Resumo}

Este artigo tem como objetivo analisar como práticas de Green Supply Chain Management (GSCM) estão sendo induzidas, tanto interna quanto externamente, por empresas consideradas focais em suas cadeias de suprimentos localizadas no Brasil e atuantes no segmento de alta tecnologia. Foram realizados oito estudos de casos por meio da triangulação de fontes de dados: entrevistas, observações diretas e obtenção de dados secundários. Há mecanismos específicos para induzir práticas de GSCM internamente e externamente e destacam-se os mecanismos: treinamento ambiental, atividades logísticas, seleção e avaliação de fornecedores e marketing verde. Constatou-se também que a empresa focal é o vetor nesse processo.

Palavras-chave

Green Supply Chain Management. Mecanismos de indução. Empresas de alta tecnologia. Brasil.

\section{Introdução}

Segundo Zhu \& Sarkis (2006), a competitividade empresarial está estimulando as organizações a se diferenciarem de seus concorrentes por meio da busca de um melhor desempenho ambiental sem comprometer os resultados econômicos, considerando toda a cadeia produtiva em uma perspectiva win-win, onde tanto aspectos ambientais quanto econômicos são concomitantemente melhorados. Consequentemente, surge uma nova abordagem gerencial, que considera tanto o contexto interno quanto o externo das organizações, denominada de Green Supply Chain Management (GSCM) (Sarkis et al., 2011; Min \& Kim, 2012).

GSCM é uma abordagem interdisciplinar que vem recebendo atenção nos últimos anos de pesquisadores e de agentes de setores industriais na adoção de uma perspectiva mais "verde" na gestão da cadeia de suprimentos (Srivastava, 2007; Sarkis et al., 2011), com o objetivo de adotar estratégias mais limpas direcionadas aos processos e produtos ao longo de sua cadeia, sendo fonte de vantagem competitiva (Vachon \& Klassen, 2006). Consideram-se fatores de relacionamento, tecnologia e práticas organizacionais no contexto das cadeias de suprimentos, que são fundamentais no processo de tomada de decisão relativo a operações internas e externas à organização (Sarkis, 2003) com um enfoque ambiental.

A discussão sobre a adoção de práticas de GSCM e seus efeitos positivos no desempenho organizacional está em fase de consolidação, e, em especial, a dúvida sobre como induzir com sucesso essas práticas de GSCM ainda não está respondida pelo estado da arte do tema. Zhu et al. (2011) afirmam que para adotar práticas de GSCM é necessário desenvolver a cooperação entre parceiros da cadeia. Uma forma de desenvolver esse processo de colaboração seria 
transferir e/ou disseminar o conhecimento sobre questões "verdes" entre as diversas empresas que compõem uma cadeia de suprimentos (Dües et al., 2012).

Entretanto, carece-se ainda de pesquisas que tenham se aprofundando na identificação e discussão dos mecanismos de indução de práticas de GSCM. Assim, em vista da necessidade em estudar em profundidade os mecanismos de indução de práticas de GSCM à montante e à jusante da cadeia de suprimentos, o presente trabalho tem como objetivo analisar como práticas de GSCM estão sendo induzidas internamente (dentro da própria empresa) e externamente (para outras empresas) por empresas focais em suas cadeias de suprimentos. Para isso, foram realizados oito estudos de casos em empresas montadoras atuantes no segmento de alta tecnologia localizadas no Brasil.

0 diferencial desta pesquisa é que, até o momento, os trabalhos disponíveis na literatura são direcionados para a sistematização conceitual de práticas de GSCM (Srivastava, 2007; Sarkis et al., 2011; Min \& Kim, 2012; Sarkis, 2012), sendo esse o perfil da maior parte dos trabalhos brasileiros (Brito \& Berardi, 2010; Pereira et al., 2011; Dias et al., 2012), ou então para compreender os efeitos da adoção de práticas de GSCM no desempenho das empresas (Hervani et al., 2005; Zhu et al., 2008a, c, 2012a; Thun \& Müller, 2010; Green Junior et al., 2012). Até onde se sabe, não foram encontrados ainda na literatura estudos qualitativos sobre a indução de práticas de GSCM entre os diversos elos das cadeias de suprimentos com foco em países em desenvolvimento. Além disso, há uma carência de estudos sobre a América Latina, e em especial sobre o Brasil, pois a maioria dos relatos de pesquisa retrata o contexto chinês ou de países desenvolvidos (Yang et al., 2010), com predominância de métodos quantitativos (como, por exemplo, survey, modelagem matemática e congêneres).

Para atingir o objetivo proposto, este artigo está estruturado em cinco seções, sendo a primeira delas de lntrodução, que apresenta o objetivo do artigo e sua justificativa; a segunda de Revisão de literatura, a qual apresenta os conceitos de práticas de GSCM e os mecanismos de indução; a terceira de Método de pesquisa, que caracteriza o objeto de estudo e descreve os procedimentos de coleta e análise dos dados; a quarta de Resultados e discussões, e a quinta de Conclusões da pesquisa, com destaque para as contribuições da pesquisa.

\section{Revisão de literatura}

\subsection{Práticas de Green Supply Chain Management}

GSCM é considerada uma abordagem conceitual híbrida ao integrar fundamentos de gestão ambiental com pressupostos de gestão da cadeia de suprimentos (Srivastava, 2007). Esse novo conceito leva em consideração a preocupação ambiental em atividades de cadeia de suprimentos, como por exemplo: projeto do produto; compras; manufatura; transporte e marketing; e logistica reversa (Hervani et al., 2005). Seu objetivo é integrar as operações fabris com as questões ambientais, a fim de reduzir custos operacionais do ciclo de vida do produto e, ao mesmo tempo, diminuir a geração de poluição e resíduos e de consequentes problemas de saúde (Beamon, 1999; Thun \& Müller, 2010).

Há várias classificações para práticas de GSCM, mas Zhu et al. (2008c) conseguiram, por meio de uma survey, validar estatisticamente os seus constructos. Portanto, nesta pesquisa, as práticas de GSCM consideradas são, principalmente, as sugeridas por tais autores:

- Gestão ambiental interna;

- Compras verdes;

- Cooperação com cliente;

\section{- Ecodesign;}

- Recuperação do investimento.

Deve-se acrescentar ainda a prática de logística reversa, tendo em vista as sugestões de Srivastava (2007) e de Sarkis et al. (2011).

Assim, seguem as práticas de GSCM consideradas neste trabalho e suas respectivas definições (Tabela 1).

Entretanto, há fatores que devem ser considerados no processo de adoção de práticas de GSCM, como a indução de práticas entre os elos da cadeia, portanto, na próxima seção, são identificados os mecanismos de indução de GSCM encontrados na literatura.

\subsection{Mecanismos para indução de práticas de GSCM}

Nesta pesquisa, entende-se por indução o ato empregado pela empresa focal a fim de mobilizar tanto o ambiente interno como o externo (fornecedores e clientes) a adotarem práticas de GSCM ao longo da cadeia de suprimentos.

A indução da adoção de práticas de GSCM nas empresas ocorre interna ou externamente com fornecedores e clientes de maneira a gerar inovação 
Tabela 1. Definições das práticas de GSCM.

\begin{tabular}{|c|c|}
\hline Práticas de GSCM & Definição \\
\hline $\begin{array}{l}\text { Gestão ambiental } \\
\text { interna }\end{array}$ & $\begin{array}{l}\text { A gestão ambiental interna é considerada o primeiro passo para a implementação e adoção de outras práticas } \\
\text { de GSCM (Zhu \& Sarkis, 2006). Para isso, devem-se adotar programas internos de gestão ambiental com o } \\
\text { comprometimento da alta e média administração e cooperação interfuncional (Zhu et al., 2008b, c, 2012a; } \\
\text { Xu et al., 2012), programas de auditoria interna e externa à empresa (Darnall et al., 2008; Large \& Thomsen, } \\
\text { 2011) e adoção de sistema de gestão ambiental com base na } 1 S 014001 \text { (Arimura et al., 2011). }\end{array}$ \\
\hline Compras verdes & $\begin{array}{l}\text { Compras verdes envolvem atividades de compra com fornecedores com o objetivo de reduzir o resíduo na fonte e } \\
\text { o consumo de materiais virgens (Carter et al., 2000; Min \& Galle, 2001). }\end{array}$ \\
\hline Cooperação com cliente & $\begin{array}{l}\text { A colaboração com os clientes inclui o intercâmbio de informações técnicas e operacionais a fim de planejar e } \\
\text { definir metas ambientais (Eltayeb et al., 2010). }\end{array}$ \\
\hline \multirow[t]{4}{*}{ Ecodesign } & $\begin{array}{l}0 \text { ecodesign, conhecido como DFE (design for environment), tem como objetivo criar produtos ecoeficientes, } \\
\text { sem comprometer seus custos, qualidade e restrições de tempo para a fabricação. Um dos aspectos-chave é } \\
\text { facilitar o reuso, reciclagem e recuperação. O sucesso do projeto do produto requer cooperação entre a empresa } \\
\text { e seus parceiros da cadeia de suprimentos (Zhu et al., 2008c), seja ao projetar embalagens em parceria com } \\
\text { os fornecedores, seja ao projetar produtos em parceria com clientes (Diabat \& Govindan, 2011) na busca de } \\
\text { minimizar a geração de resíduos e o impacto ambiental do produto durante todo ciclo de vida (Srivastava, 2007). } \\
\text { Assim, conforme apresentado por Dües et al. (2012), o ecodesign visa: }\end{array}$ \\
\hline & - Design de produto para reduzir consumo de material e/ou energia; \\
\hline & - Design de produto para reuso ou reciclagem ou recuperação de componentes; \\
\hline & - Design de produto para evitar ou reduzir o uso de substâncias perigosas no processo de fabricação. \\
\hline $\begin{array}{l}\text { Recuperação do } \\
\text { investimento }\end{array}$ & $\begin{array}{l}0 \text { objetivo da recuperação do investimento é gerenciar estoque ao vender excesso de inventário, sucata, } \\
\text { equipamentos e materiais usados (Preuss, 2005; Zhu et al., 2008a, c, 2011; liu et al., 2011). }\end{array}$ \\
\hline Logística reversa & $\begin{array}{l}\text { A logística reversa é o processo de planejar, implantar e controlar o fluxo de materiais, inventários, bens acabados } \\
\text { e informações relacionadas ao ponto de consumo até o ponto de origem para captar valor do produto (reuso, } \\
\text { remanufatura e/ou reciclagem) ou mesmo descartar de maneira adequada (Rogers \& Tibben-Lembke, 1999), 1999). }\end{array}$ \\
\hline
\end{tabular}

e alcançar eficiências ambientais, operacionais e, consequentemente, obter resultado econômico satisfatório (Zhu et al., 2012b). Cabe ressaltar, entretanto, que a preocupação ambiental inicia-se de dentro para fora da empresa, passando a envolver fornecedores e clientes imediatos. Então, para que haja eficiência na cadeia, os fornecedores e clientes devem possuir uma relação de cooperação (Zhu et al., 2011), confiança mútua (Prajogo \& Olhager, 2012) e compartilhamento de conhecimento (Cao et al., 2010).

Em geral, induzir a adoção de práticas de GSCM pode ocorrer internamente na empresa e externamente junto a fornecedores por meio de workshops e palestras para os funcionários (Liu et al., 2011; Sarkis, 2012). Já com os clientes pode ocorrer com o marketing verde e a rotulagem ambiental (Sarkis, 2012; Chan et al., 2012; Andiç et al., 2012).

Workshops e palestras são formas de orientar, capacitar e treinar funcionários e fornecedores a aprenderem e a terem objetivos ambientais comuns (Liu et al., 2011; Sarkis, 2012). Por isso, fatores humanos são importantes para induzir práticas de GSCM. No entanto, firmar parcerias e colaboração com fornecedores é um processo demorado e dispendioso que requer suporte, assistência, treinamento (Bai \& Sarkis, 2010; Large \& Thomsen, 2011; Fu et al., 2012), e para isso o relacionamento deve ser consolidado por meio de contrato de longo prazo (Sharfman et al., 2009; Gaussin et al., 2011).

Outros mecanismos de indução são marketing verde, por incentivar consumidores a se engajarem na logística reversa devolvendo o produto no final da vida útil, orientando-os com um guia de usuário ambientalmente consciente, além de rotulagem ambiental, como maneira de incentivar consumidores a comprarem seus produtos (Andiç et al., 2012; Gaussin et al., 2011).

Por fim, atenção deve ser dada aos programas voltados aos fornecedores como, por exemplo, seleção, avaliação, desenvolvimento (Lee et al., 2009; Large \& Thomsen, 2011; Gimenez \& Tachizawa, 2012), monitoramento e auditoria na melhoria do desempenho ambiental e na formação de equipe de projetos conjuntos tanto interno quanto com fornecedores, no cumprimento dos objetivos ambientais da cadeia de suprimentos (Vachon, 2007; Yang \& Sheu, 2007; Andiç et al., 2012; Green Junior et al., 2012).

\section{Método de pesquisa}

\subsection{Objeto de estudo}

Os países emergentes - como Brasil, Rússia, Índia e China (BRIC) - cada vez mais têm sido avaliados em termos de atratividade e competitividade de seus mercados. Dentre os integrantes do BRIC, o Brasil se destaca em vários fatores, tais como a estabilidade da estrutura macroeconômica, sua política democrática, e por possuir um vasto território, rico em recursos naturais (Hauser et al., 2007). 
Em função da busca da preservação de seus recursos naturais, o governo brasileiro sancionou a Nova Política Nacional de Resíduos Sólidos em 2010, que tem como objetivo estabelecer diretrizes para o descarte ambientalmente correto de resíduos eletrônicos, responsabilizando os fabricantes a adotarem medidas que priorizem a logística reversa (Brasil, 2010).

Os resíduos de produtos eletrônicos possuem materiais danosos ao meio ambiente, como o lítio, o cádmio, o mercúrio, o berílio, entre outros. Esses componentes, no final da vida útil do produto, quando descartados de maneira incorreta, em aterros ou em lugares inapropriados, podem gerar problemas graves de contaminação e impactos no meio ambiente (Araújo et al., 2012).

Tendo em vista os argumentos colocados anteriormente, decidiu-se, nesta pesquisa, estudar algumas empresas do segmento de alta tecnologia (montadoras de computadores e impressoras) localizadas no Brasil.

\subsection{Procedimentos de coleta e análise de dados}

Na seleção das empresas para compor este estudo, buscaram-se informações e contatos de empresas montadoras de produtos de alta tecnologia no site da Associação Brasileira da Indústria Elétrica e Eletrônica (ABINEE). A preferência foi escolher empresas de grande porte, de renome no mercado e de grande representatividade nas vendas, seja no mercado internacional seja no mercado nacional.

As empresas pré-selecionadas foram contatadas a partir do registro contido no site da ABINEE. Foram enviados e-mails para algumas empresas, na pretensão de realizar as visitas. Em resposta, oito empresas responderam ao convite e aceitaram participar da pesquisa. A pesquisa foi então realizada por uma equipe de pesquisadores, que visitaram essas oito empresas.

Conforme solicitação dos entrevistados, omitiu-se o nome das empresas da seguinte forma: 5 empresas detentoras de marca (empresas X, P, Y, H e M) e 3 empresas OEM (Original Equipment Manufacturer), importantes em nível mundial (empresas K, W e Z).

Conforme apresentado no Tabela 2, como fonte de coleta de dados, a pesquisa utilizou a técnica de triangulação das fontes de informação para buscar maior confiabilidade do estudo de casos. As pessoas/ profissionais selecionadas para as entrevistas estão relacionadas aos temas centrais desta pesquisa (gestão ambiental, cadeia e suprimentos, área tecnológica, inovação ambiental e manufatura). Além da aplicação do questionário aos entrevistados, realizaram-se observações diretas nas empresas, no "chão de fábrica", nos painéis informativos (metas ambientais, política integrada de gestão) no decorrer da visita; e obtiveram-se dados secundários, como materiais impressos (folders) e digitais (apresentação no Power Point, documentos no Word e Excel). Por fim, também foram analisadas informações pertinentes no website das empresas.

0 questionário de pesquisa foi elaborado para obter informações sobre: 1) caracterização das empresas; 2) estrutura de suas cadeias de suprimentos; e 3) práticas de GSCM, em que foram identificadas as práticas adotadas pelas empresas montadoras e como as empresas focais induzem essas práticas em suas cadeias de suprimentos.

A análise dos dados foi baseada na convergência entre a teoria e a realidade das empresas estudadas. Foi elaborado um resumo dos depoimentos dos entrevistados, com base em anotações e observações durante as entrevistas e então interpretadas à luz da

Tabela 2. Dados da pesquisa de campo.

\begin{tabular}{|c|c|c|c|c|c|c|c|c|}
\hline Empresa & $x$ & K & W & Y & Z & $\mathrm{H}$ & $M$ & $P$ \\
\hline Entrevistados & $\begin{array}{l}\text { - Analista } \\
\text { ambiental }\end{array}$ & $\begin{array}{l}\text { - Supervisor } \\
\text { ambiental } \\
\text { - Coordenador } \\
\text { de projetos } \\
\text { - Analista de } \\
\text { sistemas }\end{array}$ & $\begin{array}{l}\text { - Assistente de } \\
\text { qualidade } \\
\text { - Analista de } \\
\text { qualidade } \\
\text { - Auxiliar de } \\
\text { qualidade } \\
\text { vSupply quality } \\
\text { engineering }\end{array}$ & $\begin{array}{l}\text { - Coordenador } \\
\text { de projeto de } \\
\text { responsabilidade } \\
\text { social e } \\
\text { ambiental } \\
\text { na cadeia de } \\
\text { suprimentos }\end{array}$ & $\begin{array}{l}\text { - Analista } \\
\text { de qualidade } \\
\text { (coordenador } \\
\text { de projeto de } \\
\text { responsabilidade } \\
\text { social e } \\
\text { ambiental) } \\
\text { - Engenheiro de } \\
\text { qualidade }\end{array}$ & $\begin{array}{l}\text { - Engenheira } \\
\text { de saúde e } \\
\text { segurança } \\
\text { ocupacional } \\
\text { - Gestor de } \\
\text { suprimentos }\end{array}$ & $\begin{array}{l}\text { - Coordenador } \\
\text { de meio } \\
\text { ambiente } \\
\text { - Engenheiro de } \\
\text { manufatura }\end{array}$ & $\begin{array}{l}\text { - Coordenador } \\
\text { de } \\
\text { sustentabilidade } \\
\text { ambiental } \\
\text { - Assistente de } \\
\text { qualidade }\end{array}$ \\
\hline Duração & $\begin{array}{l}4 \text { horas e } \\
30 \text { minutos }\end{array}$ & $\begin{array}{l}6 \text { horas e } \\
30 \text { minutos }\end{array}$ & 3 horas & 4 horas & $\begin{array}{l}2 \text { horas e } \\
30 \text { minutos }\end{array}$ & $\begin{array}{l}2 \text { horas e } \\
30 \text { minutos }\end{array}$ & $\begin{array}{l}2 \text { horas e } \\
30 \text { minutos }\end{array}$ & 2 horas \\
\hline $\begin{array}{l}\text { Fontes de } \\
\text { dados }\end{array}$ & $\begin{array}{l}\text { Dados primários: } \\
\text { - Entrevista } \\
\text { - Visita } \\
\text { - Observação } \\
\text { Dados } \\
\text { secundários: } \\
\text { - Website }\end{array}$ & $\begin{array}{l}\text { Dados primários: } \\
\text { - Entrevista } \\
\text { - Visita } \\
\text { - Observação } \\
\text { Dados } \\
\text { secundários: } \\
\text { - Website } \\
\text { - Power point } \\
\text { - Folders }\end{array}$ & $\begin{array}{l}\text { Dados primários: } \\
\text { - Entrevista } \\
\text { - Visita } \\
\text { - Observação } \\
\text { Dados } \\
\text { secundários: } \\
\text { - Website } \\
\text { - Folders }\end{array}$ & $\begin{array}{l}\text { Dados primários: } \\
\text { - Entrevista } \\
\text { - Visita } \\
\text { - Observação } \\
\text { Dados } \\
\text { secundários: } \\
\text { - Website } \\
\text { - Power point } \\
\text { - Folders }\end{array}$ & $\begin{array}{l}\text { Dados primários: } \\
\text { - Entrevista } \\
\text { - Visita } \\
\text { - Observação } \\
\text { Dados } \\
\text { secundários: } \\
\text { - Website }\end{array}$ & $\begin{array}{l}\text { Dados primários: } \\
\text { - Entrevista } \\
\text { - Visita } \\
\text { Dados } \\
\text { secundários: } \\
\text { - Website }\end{array}$ & $\begin{array}{l}\text { Dados primários: } \\
\text { - Entrevista } \\
\text { - Visita } \\
\text { - Observação } \\
\text { Dados } \\
\text { secundários: } \\
\text { - Website } \\
\text { - Power point } \\
\text { - Folder }\end{array}$ & $\begin{array}{l}\text { Dados primários: } \\
\text { - Entrevista } \\
\text { - Visita } \\
\text { - Observação } \\
\text { Dados } \\
\text { secundários: } \\
\text { - Website } \\
\text { - Power point }\end{array}$ \\
\hline
\end{tabular}


teoria. Por fim, foram desenvolvidas análises a partir do cruzamento de dados de todos os casos.

\section{Resultados e Discussões}

\subsection{Estrutura da cadeia de suprimentos das empresas estudadas}

A estrutura da cadeia de suprimentos das montadoras estudadas é dividida em dois tipos: empresas detentora da marca (X, P, Y, H e M) que são montadoras de seus próprios produtos eletrônicos e são as empresas focais em suas cadeias de suprimentos; e empresas OEM (K, W e Z), que são empresas terceirizadas e especializadas em montagem de produtos eletrônicos para clientes detentores da marca, ou seja, elas produzem conforme o pedido da empresa detentora da marca. Nesses casos, uma empresa OEM segue as diretrizes da empresa focal de suas cadeias de suprimentos, que são as empresas contratantes, ou seja, as detentoras da marca. 0 esquema genérico da estrutura da cadeia de suprimentos das montadoras estudadas pode ser visto na Figura 1.

Em relação ao fornecimento de matérias-primas, nos oito casos, $80 \%$ das peças e componentes eletrônicos são provenientes do mercado internacional, em especial China e Estados Unidos, outros insumos, como por exemplo embalagem, são provenientes do mercado nacional.

À jusante, as cadeias de suprimentos são compostas pelos clientes intermediários, como varejo, consumidores que podem adquirir o produto ou pelo varejo ou pelo site da empresa detentora da
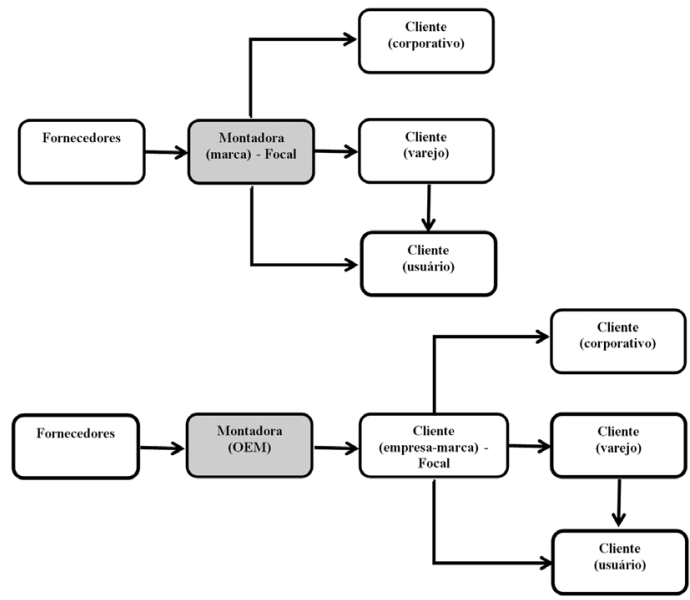

Figura 1. Esquema genérico das cadeias de suprimentos das montadoras estudadas (primeiro esquema refere-se a empresas detentoras da marca; segundo esquema refere-se a empresas OEM). marca; e corporativo (empresas privadas e públicas), cujos pedidos são realizados diretamente à empresa detentora da marca ou por licitação pública.

Devido à Nova Política Nacional de Resíduos Sólidos, estabelecida pelo governo brasileiro, as empresas detentoras da marca ( $\mathrm{X}, \mathrm{Y}, \mathrm{H}, \mathrm{M}$ e $\mathrm{P}$ ) são obrigadas a destinar de maneira correta o produto no final de sua vida útil. Assim, elas têm que recolhê-los e destina-los cada vez mais à reciclagem, e, para isso, as empresas detentoras da marca ou executam a atividade ou contratam empresas terceirizadas para a coleta, descaracterização do produto, separação de peças e componentes e envio aos recicladores homologados.

\subsection{Práticas de GSCM}

As práticas de GSCM mais adotadas nas empresas estudadas são: gestão ambiental interna, recuperação de investimentos e logística reversa. A adoção de práticas de ecodesign e compras verdes estão condicionadas a iniciativas das matrizes das empresas detentoras da marca e das empresas clientes das OEM. A cooperação com o cliente é ainda tímida e ocorre apenas como apoio à prática de logística reversa.

Em termos gerais, as formas pelas quais as práticas de GSCM são adotadas nas empresas estudadas são:

- Gestão ambiental interna, por meio de certificação ISO 14001 e metas ambientais na fábrica;

- Compras verdes, incluindo a seleção de fornecedores com base na RoHS (Restriction of Hazardous Substances Directive) e em certificações 1SO, e realização de auditorias frequentes, como base, por exemplo, na EICC (Electronic Industry Citizenship Coalition);

- Cooperação com o cliente, por meio do apoio às iniciativas de logística reversa (usando o site das empresas, que possuem programas de reciclagem);

- Ecodesign, envolvendo centro de P\&D (pesquisa e desenvolvimento) e parceria com cliente;

- Recuperação do investimento, com venda de materiais para empresa recicladora homologada;

- Logística reversa, com uma área interna na empresa para separação, reuso e destinação correta, contratação de empresa recicladora homologada e existência de pontos de coleta próprios da empresa (por exemplo, assistência técnica).

\subsection{Indução da adoção de práticas de GSCM: mecanismos relevantes}

A seguir, são destacados em negrito os principais mecanismos de indução de práticas de GSCM nas empresas estudadas. 


\subsubsection{Internamente}

Ao induzir práticas de GSCM com fornecedores e clientes, as montadoras devem ter, primeiramente, uma gestão ambiental interna consolidada, na qual estejam a alta administração e os funcionários comprometidos e alinhados com os objetivos ambientais.

Para executar as atividades de gestão ambiental interna, todas as empresas, com exceção de $\mathrm{H}$, desenvolvem seus funcionários por meio de treinamentos, cursos de educação e orientação ambiental, workshop e palestra a respeito de questões ambientais para que esses funcionários aprendam e estejam comprometidos com a temática, confirmando os indícios de liu et al. (2011) e Sarkis (2012).

Todas as empresas, com exceção de $\mathrm{H}$, também realizam monitoramento das operações internas e realizam auditorias de conformidade para acompanhar os indicadores de desempenho operacional e ambiental.

Em relação ao final do processo produtivo, todas as montadoras estão buscando recuperar o investimento, com exceção de $\mathrm{H}$, ao adotar uma política de reuso, remanufatura e/ou reciclagem de materiais, substâncias e/ou produtos inservíveis.

A recuperação do investimento busca reinserir materiais e produtos no processo produtivo ou vendê-los aos recicladores homologados pela empresa, por isso ela está entrelaçada com a logística, uma vez que os materiais e componentes usados são revendidos aos recicladores. Em vista disso, uma maneira de induzir a prática de recuperação do investimento seria adotar estratégias nas atividades de logística (empresas X, Y, M, P, K, W e Z). De acordo com Lu $\&$ Lin (2012), a logística de transporte é um fator determinante para a consciência ambiental da cadeia de suprimentos.

A empresa $\mathrm{H}$ é uma exceção no que tange às empresas detentoras da marca porque a sua filosofia de gestão é a global outsourcing, então ela não possui uma unidade produtiva, apenas escritórios administrativos no Brasil.

\subsubsection{Com fornecedores}

A cadeia de suprimentos do setor eletroeletrônico é complexa, devido principalmente à existência de fornecedores globais e locais, o que necessita de uma melhor coordenação à montante da cadeia. Por isso, induzir práticas de GSCM com fornecedores se torna um desafio, já que a parceria é diferente entre fornecedores de componentes importados e entre fornecedores de componentes nacionais.

A indução com fornecedores globais é pouco difundida, já que o relacionamento entre a montadora e eles em geral é geograficamente difícil, sendo responsabilidade das matrizes das empresas multinacionais (empresas detentora da marca) a função de induzir eventuais práticas de GSCM.

Com os fornecedores locais são induzidas às práticas de compras verdes e ecodesign de embalagem.

A prática de compras verdes visa adquirir insumos que não sejam nocivos ao meio ambiente, como, por exemplo, a pasta de solda lead-free e os solventes à base d'água, seguindo rigorosamente os critérios estabelecidos pela RoHS. Mas, para isso, as empresas (X, Y, H, M e P) estão buscando selecionar, avaliar, monitorar e desenvolver fornecedores (Lee et al., 2009; Large \& Thomsen, 2011; Gimenez \& Tachizawa, 2012; Green Junior et al., 2012) por meio de critérios ambientais nos contratos e parcerias com esses fornecedores durante o processo de compra (Sharfman et al., 2009; Gaussin et al., 2011). Assim, geralmente a seleção de fornecedores é baseada em preço e qualidade, mas as empresas estão também priorizando o critério ambiental, como, por exemplo, a existência de um sistema de gestão ambiental, como a ISO 14001 (empresas X e P), ou se seus fornecedores (no caso as montadoras OEM) estão seguindo as diretivas internacionais como a EICC, a RoHS e a SER (Social and Environmental Responsibility) (empresas Y e M). Já a avaliação de fornecedores é definida segundo o desempenho comparativo e progressivo com base em padrões legislativos locais e internacionais, como a emissão de gases de efeito estufa e geração de resíduos durante o processo produtivo, bem como manuseio e descarte de resíduos no meio ambiente, seguindo assim as diretrizes da Nova Política de Resíduos Sólidos e a diretiva WEEE (Waste Electrical and Electronic Equipment Directive), tentando-se evitar eventuais passivos ambientais. As montadoras (X, Y, $\mathrm{H}, \mathrm{M}$ e P) fazem as avaliações por meio de auditoria, acompanhando desempenho operacional e ambiental dos fornecedores em períodos semestrais ou anuais.

Há uma diferença na seleção e auditoria de fornecedores quando a montadora é a empresa OEM ou empresa detentora da marca, já que essas atividades ficam restritas à empresa detentora da marca, que define com quais fornecedores as montadoras OEM devem negociar.

A prática de ecodesign de embalagem tem como objetivo minimizar o uso de matéria-prima, de geração de resíduos, de reduzir espaço físico para facilitar a logística e, principalmente, de utilizar materiais reciclados e torná-los mais recicláveis. Para isso, as empresas detentoras da marca ( $\mathrm{X}, \mathrm{K}$ e $\mathrm{Y}$ ) estão desenvolvendo os fornecedores locais para alcançar eficiência e melhorar o desempenho nos processos e nos produtos. Então, as montadoras firmam parceria com seus fornecedores e utilizam equipes de 
trabalho (Zhu et al., 2011) que irão auxiliá-los para melhorar seus padrões ambientais, seja nos processos produtivos seja na embalagem, bem como realizam workshops e palestras sobre temas ambientais para os fornecedores (Liu et al., 2011; Sarkis, 2012).

\subsubsection{Com clientes}

A cooperação com cliente para o ecodesign depende da posição da empresa focal em sua cadeia de suprimentos. Se as montadoras são as empresas detentoras da marca, dificilmente haverá participação de clientes na adoção dessa prática de GSCM, uma vez que seus clientes são o varejo e os consumidores finais, a menos que os clientes sejam empresas do setor público ou privado, que podem interferir nos pedidos do produto (critérios de licitação). No entanto, se as montadoras são as empresas OEM, a cooperação do cliente (empresa detentora da marca) é fundamental no alcance dos objetivos ambientais e, principalmente, na adoção dessa prática de GSCM.

0 caso da montadora OEM $\mathrm{K}$ é o único dentre os oito que adota a prática de cooperação com o cliente para o ecodesign. Para induzir tal prática com os clientes, a empresa focal (detentora da marca) estabelece colaboração formando um grupo de projeto para fazer o desenho do produto almejado, bem como desenvolver produtos que se adequem aos selos e rótulos ambientais, como, por exemplo, selo Energy Star. Esse selo comprova que o produto é ecoeficiente, ou seja, consome menos energia em comparação a seus congêneres.

Outra maneira de induzir essa prática é por meio do workshop e palestras (Liu et al., 2011; Sarkis, 2012) para clientes sobre como essas empresas podem cooperar entre si na busca de melhorias ambientais.

Já a indução entre montadora detentora da marca e seus clientes (consumidores) tende a ocorrer durante a adoção das práticas de recuperação do investimento e da logística reversa, já que ambas estão diretamente relacionadas, pois seu sucesso depende exclusivamente da participação do usuário do produto.

A prática de logística reversa depende da participação e cooperação de seus clientes, ou seja, dos usuários, uma vez que são eles que entram em contato com as empresas detentoras da marca para destinar de maneira correta o seu produto no final de sua vida útil. Para que isso ocorra, as empresas detentoras da marca fazem uso do marketing verde (Andiç et al., 2012; Gaussin et al., 2011) (X, M e P), seja por meios eletrônicos (website), seja pelo Serviço de Atendimento ao Consumidor (SAC). 0 usuário entrega o produto no ponto de coleta para que empresas terceirizadas façam a retirada e a reciclagem, com a consequente destinação correta de produto.
As empresas montadoras OEM não realizam a logística reversa, pois, segundo a legislação brasileira, a logística reversa é de responsabilidade das empresas detentoras da marca.

Para melhor entendimento dos resultados desta pesquisa, foram apresentadas, de maneira resumida no Tabela 3, as práticas de GSCM e suas formas de indução nas empresas analisadas.

0 resultado da pesquisa mostra que há mais mecanismos de indução de práticas de GSCM com fornecedores do que clientes, porém o êxito na adoção desses mecanismos depende mais de ações advindas dos clientes (montadora detentora da marca),

Tabela 3. Comparação entre as empresas estudadas.

\begin{tabular}{|c|c|c|}
\hline Empresa & Práticas de GSCM & Formas de inducão \\
\hline $\begin{array}{c}\mathrm{X} \\
\text { (nacional) }\end{array}$ & $\begin{array}{l}\text { 1) Gestão ambiental } \\
\text { interna } \\
\text { 2) Compras verdes } \\
\text { 3) Ecodesign de } \\
\text { embalagem } \\
\text { 4) Recuperação do } \\
\text { investimento } \\
\text { 5) Logística reversa }\end{array}$ & $\begin{array}{l}\text { 1) Com fornecedores } \\
\text { a. Seleção, avaliação, auditoria } \\
\text { e desenvolvimento } \\
\text { b. Workshop e palestra } \\
\text { c. Trabalho em equipe } \\
\text { 2) Internamente } \\
\text { a. Treinamento de funcionários } \\
\text { b. Auditoria } \\
\text { c. Atividade de logística } \\
\text { 3) Com clientes } \\
\text { a. Marketing verde }\end{array}$ \\
\hline $\begin{array}{c}\mathrm{K} \\
\text { (multinacional) }\end{array}$ & $\begin{array}{l}\text { 1) Gestão ambiental } \\
\text { interna } \\
\text { 2) Ecodesign de } \\
\text { embalagem e produto } \\
\text { 3) Cooperação com } \\
\text { cliente } \\
\text { 4) Recuperação do } \\
\text { investimento }\end{array}$ & $\begin{array}{l}\text { 1) Com fornecedores } \\
\text { a. Avaliação, monitoramento e } \\
\text { desenvolvimento } \\
\text { b. Workshop e palestra } \\
\text { c. Trabalho em equipe } \\
\text { 2) Internamente } \\
\text { a. Treinamento de funcionários } \\
\text { b. Auditoria } \\
\text { c. Atividade de logística } \\
\text { 3) Com clientes } \\
\text { a. Workshop e palestra } \\
\text { b. Parceria e trabalho em equipe }\end{array}$ \\
\hline $\begin{array}{c}\text { W } \\
\text { (multinacional) }\end{array}$ & $\begin{array}{l}\text { 1) Gestão ambiental } \\
\text { interna } \\
\text { 2) Recuperação do } \\
\text { investimento }\end{array}$ & $\begin{array}{l}\text { 1) Com fornecedores } \\
\text { a. Avaliação e monitoramento } \\
\text { 2) Internamente } \\
\text { a. Treinamento de funcionários } \\
\text { b. Auditoria } \\
\text { c. Atividade de logística } \\
\text { 3) Com clientes } \\
\text { a. Não há }\end{array}$ \\
\hline$\underset{\text { (multinacional) }}{\mathrm{Y}}$ & $\begin{array}{l}\text { 1) Gestão ambiental } \\
\text { interna } \\
\text { 2) Compras verdes } \\
\text { 3) Ecodesign de } \\
\text { embalagem } \\
\text { 4) Recuperação do } \\
\text { investimento } \\
\text { 5) Logística reversa }\end{array}$ & $\begin{array}{l}\text { 1) Com fornecedores } \\
\text { a. Seleção, avaliação, auditoria } \\
\text { e desenvolvimento } \\
\text { b. Workshop e palestra } \\
\text { c. Trabalho em equipe } \\
\text { 2) Internamente } \\
\text { a. Treinamento de funcionários } \\
\text { b. Auditoria } \\
\text { c. Atividade de logística } \\
\text { 3) Com clientes } \\
\text { a. Marketing verde }\end{array}$ \\
\hline$\frac{\mathrm{Z}}{\text { (multinacional) }}$ & $\begin{array}{l}\text { 1) Gestão ambiental } \\
\text { interna } \\
\text { 2) Recuperação do } \\
\text { investimento }\end{array}$ & $\begin{array}{l}\text { 1) Com fornecedores } \\
\text { a. Avaliação e monitoramento } \\
\text { 2) Internamente } \\
\text { a. Treinamento de funcionários } \\
\text { b. Auditoria } \\
\text { c. Atividade de logística } \\
\text { 3) Com clientes } \\
\text { a. Não há }\end{array}$ \\
\hline$\underset{\text { (multinacional) }}{\mathrm{H}}$ & $\begin{array}{l}\text { 1) Gestão ambiental } \\
\text { interna } \\
\text { 2) Compras verdes }\end{array}$ & $\begin{array}{l}\text { 1) Com fornecedores } \\
\text { a. Seleção, avaliação e auditoria } \\
\text { 2) Internamente } \\
\text { a. Auditoria } \\
\text { 3) Com clientes } \\
\text { a. Não há }\end{array}$ \\
\hline $\begin{array}{c}\mathrm{M} \\
\text { (multinacional) }\end{array}$ & $\begin{array}{l}\text { 1) Gestão ambiental } \\
\text { interna } \\
\text { 2) Compras verdes } \\
\text { 3) Recuperação do } \\
\text { investimento } \\
\text { 4) Logística reversa }\end{array}$ & $\begin{array}{l}\text { 1) Com fornecedores } \\
\text { a. Seleção, avaliação e auditoria } \\
\text { 2) Internamente } \\
\text { a. Treinamento de funcionários } \\
\text { b. Auditoria } \\
\text { c. Atividade de logística } \\
\text { 3) Com clientes } \\
\text { a. Marketing verde }\end{array}$ \\
\hline $\begin{array}{c}P \\
\text { (nacional) }\end{array}$ & $\begin{array}{l}\text { 1) Gestão ambiental } \\
\text { interna } \\
\text { 2) Compras verdes } \\
\text { 3) Ecodesign de } \\
\text { produto } \\
\text { 4) Recuperação do } \\
\text { investimento } \\
\text { 1) Logística reversa } \\
\end{array}$ & $\begin{array}{l}\text { 1) Com fornecedores } \\
\text { a. Seleção, avaliação e auditoria } \\
\text { 2) Internamente } \\
\text { a. Treinamento de funcionários } \\
\text { b. Auditoria } \\
\text { c. Atividade de logística } \\
\text { 3) Com clientes } \\
\text { a. Marketing verde }\end{array}$ \\
\hline
\end{tabular}




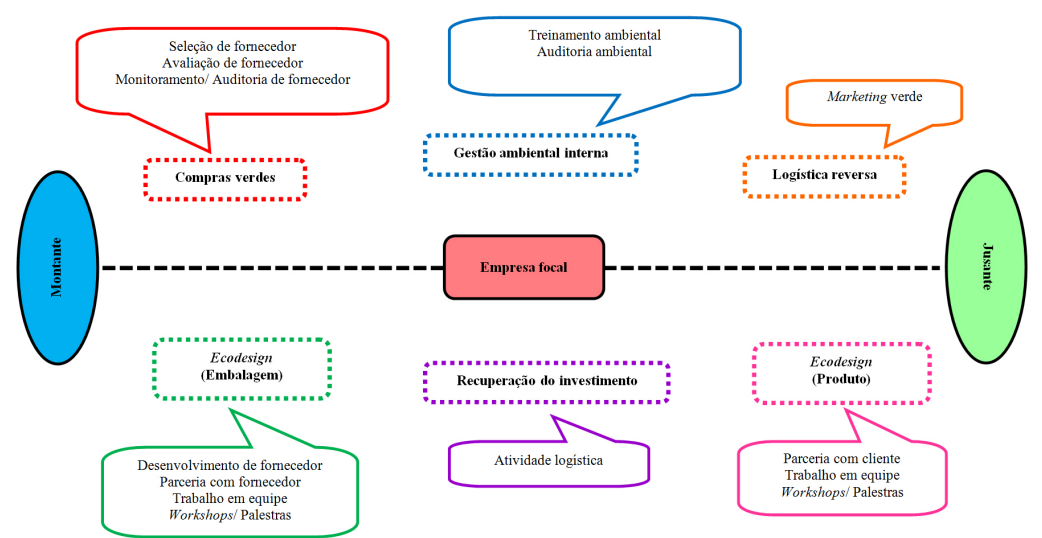

Figura 2. Framework empírico: práticas de GSCM adotadas e seus mecanismos de indução encontrados nas montadoras do segmento de alta tecnologia.

que impulsionam seus fornecedores a montante da cadeia de suprimentos. 0 elo mais forte da cadeia de suprimentos impulsiona a adoção de práticas de GSCM e, consequentemente, a sua indução.

Esses resultados podem ajudar a definir estratégias para que as empresas detentoras da marca possam seguir induzindo a adoção de práticas de GSCM em sua cadeia de suprimentos.

Na Figura 2 foram sistematizadas e relacionadas, de acordo com o resultado dos oito estudos de casos, as práticas de GSCM e suas respectivas formas de indução. Tal framework pode servir como diretriz para auxiliar montadoras do segmento de alta tecnologia a induzirem práticas de GSCM em suas cadeias, seja à montante com fornecedores, seja internamente na empresa, seja à jusante com clientes, e, assim, buscarem melhorias nos processos operacionais e ambientais em toda a cadeia de suprimentos.

\section{Conclusão}

Este artigo teve como objetivo analisar como práticas de GSCM estão sendo induzidas interna e externamente por empresas focais em suas cadeias de suprimentos e, para tanto, fez uso de estudo de múltiplos casos em empresas do setor de alta tecnologia localizadas no Brasil.

Para cada prática de GSCM aqui considerada foram identificados os principais mecanismos de indução. Os resultados são compatíveis com a literatura previamente revisada, destacando-se que:

- Treinamento, auditoria ambiental e atividades logísticas como meios importantes para induzir internamente práticas de GSCM;

- Marketing ambiental, parceria com cliente, trabalho em equipe e workshop/palestras são formas interessantes de envolver os clientes no processo de indução de práticas de GSCM;
- Seleção, avaliação, monitoramento, auditoria, desenvolvimento dos fornecedores e formação de parcerias, trabalhos em equipe e workshop/palestra são elementos relevantes para envolver os fornecedores nesse processo.

A indução de práticas de GSCM envolve uma relação dinâmica entre fornecedores, empresa focal e clientes. Se a montadora é empresa do tipo OEM, então a indução está diretamente dependente dos clientes (empresa detentora da marca), que são as empresas focais da cadeia, ou seja, estão à jusante. Por outro lado, se a montadora é detentora da marca, a indução depende dela, por ser ela a empresa focal de sua cadeia, ou seja, pois está à montante, envolvendo principalmente fornecedores de primeira camada. Portanto, o papel da empresa focal é essencial na indução da GSCM na cadeia de suprimentos como um todo.

Este trabalho apresentou resultados relevantes para os gestores das montadoras de alta tecnologia localizadas no Brasil ao relacionar as práticas de GSCM com seus mecanismos de indução, por meio de uma análise comparativa entre os pressupostos da literatura e o relato dos casos estudados. Portanto, essas informações poderão servir como guia para que as empresas possam orientar suas estratégias de negócio para se tornarem mais "verdes", uma vez que aqui se apresentam os mecanismos de indução de práticas de GSCM.

Sugere-se que pesquisas futuras avancem em abordagens metodológicas mistas (survey e estudo de casos) para o amadurecimento desse campo de pesquisa.

\section{Referências}

Andiç, E., Yurt, Ö., \& Baltacioglu, T. (2012). Green supply chains: Efforts and potential applications for the Turkish 
market. Resources, Conservation and Recycling, 58, 5068. http://dx.doi.org/10.1016/j.resconrec.2011.10.008

Araújo, M. G., Magrini, A., Mahler, C. F., \& Bilitewski, B. (2012). A model for estimation of potential generation of waste electrical and electronic equipment in Brazil. Waste Management, 32(2), 335-342. PMid:22014584 http://dx.doi.org/10.1016/j.wasman.2011.09.020

Arimura, T. H., Darnall, N., \& Katayama, H. (2011). Is ISO 14001 a gateway to more advanced voluntary action? The case of green supply chain management. Journal of Environmental Economics and Management, 61(2), 170182. http://dx.doi.org/10.1016/j.jeem.2010.11.003

Bai, C., \& Sarkis, J. (2010). Green supplier development: analytical evaluation using rough set theory. Journal of Cleaner Production, 18(12), 1200-1210. http://dx.doi. org/10.1016/j.jclepro.2010.01.016

Beamon, B. M. (1999). Designing the green supply chain. Logistics Information Management, 12(4), 332-342. http://dx.doi.org/10.1108/09576059910284159

Brasil. (2010). Institui a Política Nacional de Resíduos Sólidos; altera a Lei $n^{\circ}$ 9.605, de 12 de fevereiro de 1998; e dá outras providências (Lei $\mathrm{n}^{\circ} 12.305$, de 2 de agosto de 2010). Diário Oficial da República Federativa do Brasil.

Brito, R. P., \& Berardi, P. C. (2010). Vantagem competitiva na gestão sustentável da cadeia de suprimentos: um metaestudo. Revista de administracao de empresas, 50(2), 155-169.

Cao, M., Vonderembse, M. A., Zhang, Q., \& Ragu-Nathan, T. S. (2010). Supply chain collaboration: conceptualization and instrument development. International Journal of Production Research, 48(22), 6613-6635. http://dx.doi. org/10.1080/00207540903349039

Carter, C. R., Kale, R., \& Grimm, C. M. (2000). Environmental purchasing and firm performance: an empirical investigation. Transportation Research Part E, 36(3), 219228. http://dx.doi.org/10.1016/S1366-5545(99)00034-4

Chan, H. K., He, H., \& Wang, W. Y. C. (2012). Green marketing and its impact on supply chain management in industrial markets. Industrial Marketing Management, 41(4), 557562.http://dx.doi.org/10.1016/j.indmarman.2012.04.002

Darnall, N., Jolley, J., \& Handfield, R. (2008). Environmental management systems and green supply chain management: complements for sustainability? Business Strategy and the Environment, 17(1), 30-45. http:// dx.doi.org/10.1002/bse.557

Diabat, A., \& Govindan, K. (2011). An analysis of the drivers affecting the implementation of green supply chain management. Resources, Conservation and Recycling, 55(6), 659-667. http://dx.doi.org/10.1016/j. resconrec.2010.12.002

Dias, S. L. F. G., Labegalini, L., \& Csillag, J. M. (2012). Sustentabilidade e cadeia de suprimentos: uma perspectiva comparada de publicações nacionais e internacionais. Produção, 22(3), 517-533. http://dx.doi. org/10.1590/S0103-65132012005000034

Dües, C. M., Tan, K. H., \& Lim, M. (2012). Green as the new Lean: how to use lean practices as a catalyst to greening your supply chain. Journal of Cleaner Production.

Eltayeb, T. K., Zailani, S., \& Jayaraman, K. (2010). The examination on the drivers for green purchasing adoption among EMS 14001 certified companies in Malaysia. Journal of Manufacturing Technology Management, 21(2), 206225. http://dx.doi.org/10.1108/17410381011014378
Fu, X., Zhu, Q., \& Sarkis, J. (2012). Evaluating green supplier development programs at a telecomunications systems provider. International Journal of Production Economics, 140(1), 357-367. http://dx.doi.org/10.1016/j. ijpe.2011.08.030

Gaussin, M., Hu, G., Abolghasem, S., Basu, S., Shankar, M. R., \& Bidanda, B. (2011). Assessing the environmenta footprint of manufactured products: A survey of current literature. International Journal of Production Economics. http://dx.doi.org/10.1016/j.jpe.2011.12.002

Gimenez,C.,\&Tachizawa,E.M.(2012).Extending sustainability to suppliers: a systematic literature review. Supply Chain Management: An International Journal, 17(5), 531-543. http://dx.doi.org/10.1108/13598541211258591

Green Junior, K. W., Zelbst, P. J., Bhadauria, V. S., \& Meacham, J. (2012). Do environmental collaboration and monitoring enhance organizational performance? Industrial Management \& Data Systems, 112(2), 186-205.

Hauser, G., Zen, A., Selao, D., \& Garcia, P. (2007). A indústria eletrônica no Brasil e na China: um estudo comparativo e a análise das políticas públicas de estímulo a capacidade tecnológica do setor. Journal of Technology Management \& Innovation, 2(3), 85-96.

Hervani, A. A., Helms, M. M., \& Sarkis, J. (2005). Performance measurement for green supply chain management. International Journal Benchmarking, 12(4), 330-353. http://dx.doi.org/10.1108/14635770510609015

Large, R. 0., \& Thomsen, C. G. (2011). Drivers of green supply management performance: Evidence from Germany. Journal of Purchasing \& Supply Management, 17(3), 176184. http://dx.doi.org/10.1016/j.pursup.2011.04.006

Lee, A. H. 1., Kang, H. Y., Hsu, C. F., \& Hung, H. C. (2009) A green supplier selection model for high-tech industry. Expert Systems with Applications, 36(4), 7917-7927. http://dx.doi.org/10.1016/j.eswa.2008.11.052

Liu, X., Wang, L., Dong, Y., Yang, J., \& Bao, C. (2011). Case Studies of Green Supply Chain Management in China. International Journal of Economics and Management Engineering, 1(1), 22-34.

Lu, C., \& Lin, P. (2012). Introduction. International Journal of Shipping and Transport Logistics, 4(4), 303-305.

Min, H., \& Galle, W. P. (2001). Green purchasing practices of US firms. International Journal of Operations \& Production Management, 21(9), 1222-1238. http:// dx.doi.org/10.1108/EUM0000000005923

Min, H., \& Kim, 1. (2012). Green supply chain research: past, present, and future. Logistics Research, 4(1), 39-47. http://dx.doi.org/10.1007/s12159-012-0071-3

Pereira, G. M. C., Yen-Tsang, C., Manzini, R. B., \& Almeida, N. V. (2011). Sustentabilidade socioambiental: um estudo bibliométrico da evolução do conceito na área de gestão de operações. Produção, 21(4), 610-619. http://dx.doi. org/10.1590/S0103-65132011005000053

Prajogo, D., \& Olhager, J. (2012). Supply chain integration and performance: the effects of long-term relationships, information technology and sharing, and logistics integration. International Journal of Production Economics, 135(1), 514-522. http://dx.doi.org/10.1016/j. ijpe.2011.09.001

Preuss, L. (2005). Rhetoric and reality of corporate greening: a view from the supply chain management function. Business Strategy and the Environment, 14(2), 123-139. http://dx.doi.org/10.1002/bse.435 
Rogers, D. S., \& Tibben-Lembke, R. S. (1999). Going backwards: Reverse Logistics Trends and Pratices. Reno: University of Nevada, Center for Logistics Management.

Sarkis, J. (2003). A strategic decision framework for green supply chain management. Journal of Cleaner Production, 11(4), 397-409. http://dx.doi.org/10.1016/ S0959-6526(02)00062-8

Sarkis, J. (2012). A boundaries and flows perspective of green supply chain management. Supply Chain Management: An International Journal, 17(2), 202-216. http://dx.doi. org/10.1108/13598541211212924

Sarkis, J., Zhu, Q., \& Lai, K. H. (2011). An organizational theoretic review of green supply chain management literature. International Journal of Production Economics, 130(1), 1-15. http://dx.doi.org/10.1016/j. ijpe.2010.11.010

Sharfman, M. P., Shaft, T. M., \& Anex Junior, R. P. (2009). The road to cooperative supply-chain environmental management: trust and uncertainty among pro-active firms. Business Strategy and the Environment, 18(1), 1-13. http://dx.doi.org/10.1002/bse.580

Srivastava, S. K. (2007). Green supply-chain management: A state-of-the-art literature review. International Journal of Management Review, 9(1), 53-80. http://dx.doi. $\operatorname{org} / 10.1111 / j .1468-2370.2007 .00202 . x$

Thun, J. H., \& Müller, A. (2010). An empirical analysis of green supply chain management in the German automotive industry. Business Strategy and the Environment, 19(2), 119-132.

Vachon, S. (2007). Green supply chain practices and the selection of environmental technologies. International Journal of Production Research, 45(18-19), 4357-4379. http://dx.doi.org/10.1080/00207540701440303

Vachon, S., \& Klassen, R. D. (2006). Extending green practices across the supply chain: The impact of upstream and downstream integration. International Journal of Operations \& Production Management, 26(7), 795-821. http://dx.doi.org/10.1108/01443570610672248

Xu, X., Jin, C., \& Cao, Y. (2012). Smart reverse supply chain: an application of loT to green manufacturing. Applied Mechanics and Materials, 141, 493-497. http://dx.doi. org/10.4028/www.scientific.net/AMM.141.493

Yang, C-L., Lin, S.-P., Chan, Y.-H. \& Sheu, C. (2010). Mediated effect of environmental management on manufacturing competitiveness: An empirical study. International Journal of Production Economics, 123(1), 210-220. http://dx.doi.org/10.1016/j.ijpe.2009.08.017

Yang, C-L., \& Sheu, C. (2007). Achieving supply chain environment management: An exploratory study. International Journal of Technology Management, 40(13), 131-156. http://dx.doi.org/10.1504/IJTM.2007.013531

Zhu, Q., \& Sarkis, J. (2006). An inter-sectorial comparison of green supply chain management in China: Drivers and practices. Journal of Cleaner Production, 14(5), 472486. http://dx.doi.org/10.1016/j.jclepro.2005.01.003

Zhu, Q., Sarkis, J., Cordeiro, J. J., \& Lai, K.-H. (2008a). Firm-level correlates of emergent green supply chain management practices in the Chinese context. Omega, 36(4), 577-591. http://dx.doi.org/10.1016/j.omega.2006.11.009

Zhu, Q., Sarkis, J., \& Lai, K-H. (2008b). Confirmation of a measurement model for green supply chain management practices implementation. International Journal of Production Economics, 111(2), 261-273. http://dx.doi. org/10.1016/j.ijpe.2006.11.029

Zhu, Q., Sarkis, J., \& Lai, K-H. (2011). An institutional theoretic investigation on the links between internationalization of Chinese manufacturers and their environmental supply chain management. Resources, Conservation and Recycling, 55(6), 623-630. http://dx.doi.org/10.1016/j. resconrec.2010.12.003

Zhu, Q., Sarkis, J., \& Lai, K-H. (2012a). Green supply chain management innovation diffusion and its relationship to organizational improvement: an ecological modernization perspective. Journal of Engineering and Technology Management, 29(1), 168-185. http://dx.doi. org/10.1016/j.jengtecman.2011.09.012

Zhu, Q., Sarkis, J., Lai, K., \& Geng, Y. (2008c). The role of organizational size in the adoption of green supply chain management practices in China. Corporate Social Responsibility and Environmental Management, 15(6), 322-337. http://dx.doi.org/10.1002/ csr. 173

Zhu, Q., Tian, Y., \& Sarkis, J. (2012b). Diffusion of selected green supply chain management practices: an assessment of Chinese enterprises. Production Planning \& Control, 23(10-11), 1-14. http://dx.doi.org/10.1080/0 9537287.2011.642188

\title{
Adoption of Green Supply Chain Management practices: mechanisms of induction and the role of focal companies
}

\begin{abstract}
The goal of this study is to analyze how green supply chain management (GSCM) practices are induced, both internally and externally, by focal companies on their supply chains located in the Brazilian high-tech segment. Eight case studies are conducted through the triangulation of data sources: interviews, observations and secondary data collection. The findings reveal specific mechanisms for inducing GSCM practices internally and externally, the principal of which are environmental training, logistics activities, the selection and evaluation of suppliers and green marketing. The focal firm is also identified as the vector in this process, inducing the adoption of green supply chain practices in the chain as a whole.
\end{abstract}

\section{Keywords}

Green Supply Chain Management. Induction mechanisms. High-tech companies. Brazil. 